\title{
Frequency Reconfigurable Patch Antenna Controlled by PIN Diodes for Ku and K-Bands Applications
}

\author{
Iftissane El Mustapha ${ }^{1}$, Moulay Driss Belrhiti², Bri seddik², Foshi Jaouad ${ }^{1}$ \\ ${ }^{1}$ ER2TI Laboratory, Faculty of Sciences and Technics, Moulay Ismail University of Meknes, Errachidia - Morocco \\ mustapha.iftissane@gmail.com, j.foshi@yahoo.fr \\ ${ }^{2}$ Materials and Instrumentations, Department of Electrical Engineering, Moulay Ismail University of Meknès -Morocco \\ belrhiti2030@gmail.com, briseddik@gmail.com
}

\begin{abstract}
The main aim of this work is to design a reconfigurable frequency antenna for the sake of evaluating its performances for telecommunication applications in the $\mathrm{Ku}$ and $\mathrm{k}$ bands. Using the HFSS software, the proposed antenna structure is optimized with etching two rectangular slots having the same size at the radiant element level. The partial ground plane length is limited at the $\mathrm{Lg}=2 \mathrm{~mm}$ value. To achieve the desired frequency agility, a PIN diode is inserted into the microstrip line feeding the antenna structure. Depending on the states (ON/OFF) of the integrated PIN diode, several operating frequency bands are obtained. When the PIN is in the OFF state, the antenna covers two frequency bands [14.717.3] $\mathrm{GHz}$ and [20.8-26.7] GHz. However, in the ON state, the antenna operates in the [15.2 - 15.6] $\mathrm{GHz}$ band. These results show that the suggested antenna in this work is a powerful candidate for ensuring the frequency reconfigurability in the frequency domain $[14.7-26.7] \mathrm{GHz}$.
\end{abstract}

Key words : Reconfigurable Antenna, Microstrip Line, slot, Radiant element, PIN Diode.

\section{INTRODUCTION}

Thanks to their multifunctionalities and degrees of freedom, reconfigurable antennas have enormous advantages for integrating them into communication application systems [1]. These antennas can dynamically change their characteristics according to the environment [2]. The reconfigurable parameters are: frequency, polarization, radiation pattern [3]. This agility can be achieved with changing antenna's configuration (electrical or physical) [4].

The reconfigurability of the dual-band antenna frequency is recently accounted with using one of the next diodes (PIN or Varactor diode) they can also helping us to obtain land different resonance frequencies maintaining the same radiation pattern. These kind reconfigurable antennas find applications on the biomedical, radio astronomical or satellite communication [5].

In this research, we are studying a multi-frequency multiband agile antenna for radio astronomical and space applications. The proposed antenna covers the frequency range [16 - 22] GHz. This antenna structure is based on the integration of the $\mathrm{PIN}$ diode in the rayonnant element to get the $\mathrm{Ku}$ and $\mathrm{K}$ bands as an operating frequency. It allows us also to ensure the filtrate and the regulation of the frequency resonance [6]. This article is organized as follows:

In section 1, the proposed antenna structure with its key parameters is described. In section 2, the detail design process of the proposed antenna structure is discussed along with parametric study. In section 3 , the obtained simulated results after inserting PIN diode on the antenna for ensuring the frequency reconfigurability are also exposed in detail.

\section{PROPOSED ANTENNA DESIGN}

Figure 1 shows the geometry of the proposed slot antenna structure. The suggested reconfigurable antenna is printed on low-cost FR4 substrate with dielectric permittivity of $(\varepsilon r=4.4)$ and loss tangent of 0,018 .

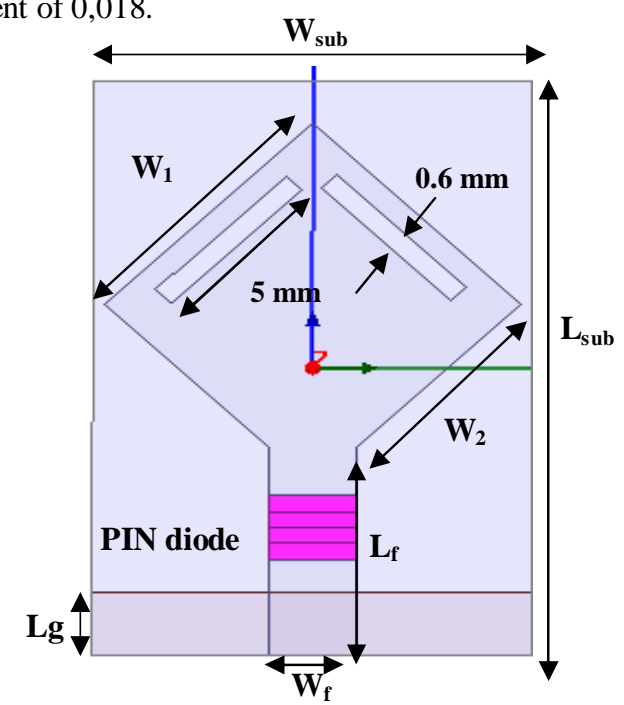

Figure 1: Geometry of the proposed slot antenna

As indicated in Figure 1, the antenna structure is composed of a square patch with two rectangular slots that have the same size. The antenna is fed with $50 \Omega$ microstrip line, and the truncated rectangular ground plane is set at $\mathrm{Lg}=2 \mathrm{~mm}$ value. All key parameters of the proposed antenna configuration are displayed in Table 1. 
Table 1: Key parameters of the proposed slot antenna

\begin{tabular}{|c|c|c|c|}
\hline Parameter & $\begin{array}{c}\text { Value } \\
(\mathbf{m m})\end{array}$ & Parameter & $\begin{array}{c}\text { Value } \\
(\mathbf{m m})\end{array}$ \\
\hline $\mathrm{W}_{1}$ & 8 & $\mathrm{~h}$ & 1.6 \\
\hline $\mathrm{W}_{2}$ & 6.33 & $\mathrm{~L}_{\mathrm{g}}$ & 2 \\
\hline $\mathrm{W}_{\text {sub }}$ & 12 & $\mathrm{~W}_{\mathrm{g}}$ & 12 \\
\hline $\mathrm{L}_{\mathrm{sub}}$ & 18 & $\mathrm{~W}_{\mathrm{f}}$ & 2.35 \\
\hline$\varepsilon_{\mathrm{r}}$ & 4.4 & $\mathrm{~L}_{\mathrm{f}}$ & 6.5 \\
\hline
\end{tabular}

\section{Parametric Study of antenna}

Figure 2 shows the preliminary geometry of the proposed antenna structure. The front view of the antenna is illustrated in Figure 2 (a), while the side view of the ordinary antenna is presented in Figure 2 (b).
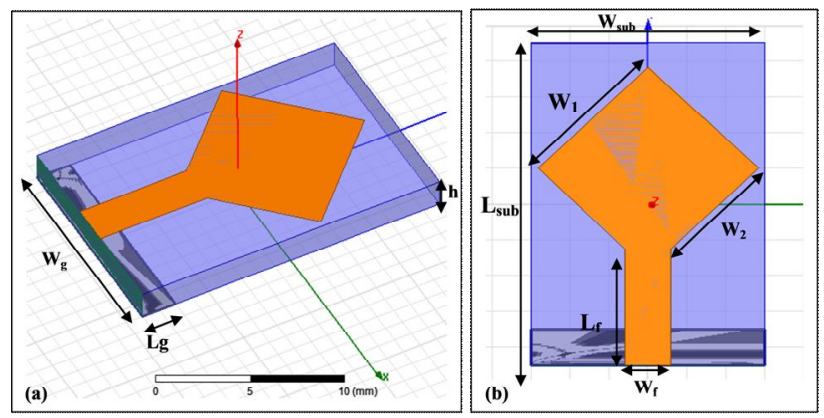

Figure 2: The geometry of the ordinary antenna structure. (a): the side view of the ordinary antenna,

(b): the front view of the ordinary antenna.

\subsection{Effect of the slots}

Parametric study is performed to obtain the final patch design and to optimize the antenna structure. In this section, we study the effect of the etched slots on the ordinary patch antenna performances. Figure 3 shows the different proposed patch antenna structure in three steps $(\mathrm{a}, \mathrm{b}$, and $\mathrm{c})$. The length of the truncated ground plane is set in $\mathrm{Lg}=2 \mathrm{~mm}$ value. The sizes of rectangular slots are fixed at $(5 \times 0,6) \mathrm{mm}^{2}$.
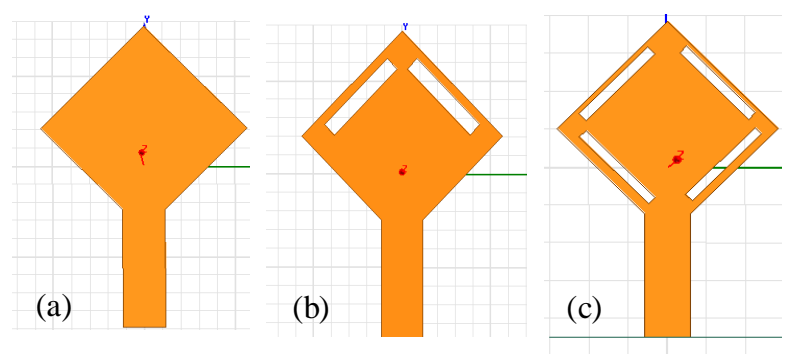

Figure 3: The patch element of the investigated antennas
(a) ordinary antenna patch
(b) antenna patch with two rectangular slots
(c) antenna patch with four rectangular slots

The evolution of the corresponding reflection coefficient curves of the last slot patch antennas ( $a, b$ and $c)$ are compared in Figure 4

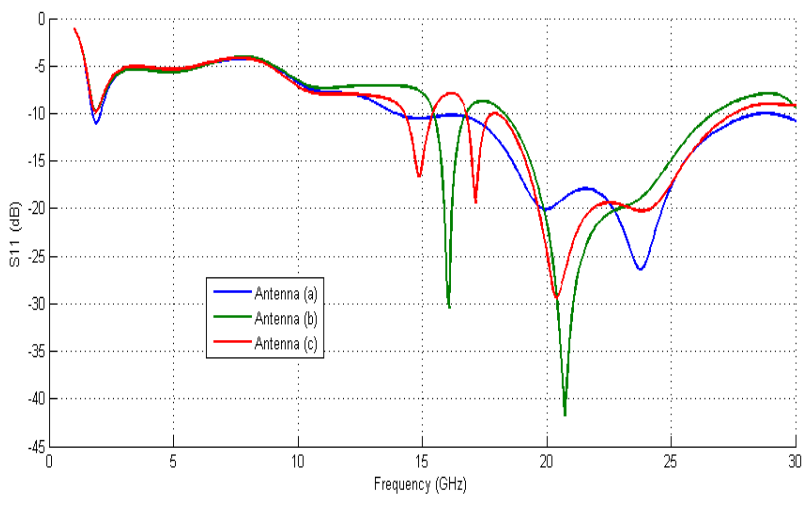

Figure 4: The frequency evolution of corresponding reflection coefficient of each investigated structure

As depicted in Figure 4, it is clear that the antenna (type a) has a broadband character but with a low reflection coefficient $\mathrm{S} 11$ which does not exceed $(\mathrm{S} 11=-26 \mathrm{~dB})$ at the resonance frequency. Whereas, the antenna type (c) has a multiband character (three operating bands) with low reflection coefficients between $-19 \mathrm{~dB}$ and $-16 \mathrm{~dB}$. For antenna type (b), it has two bands of operating frequency centered respectively at $\mathrm{fl}=16 \mathrm{GHz}(\mathrm{S} 11=-30 \mathrm{~dB})$ and $\mathrm{f} 2=20.7 \mathrm{GHz}(\mathrm{S} 11=-41 \mathrm{~dB})$. These results allow us to choose the structure type (b) as case study. With the aim of showing clearly this comparison, the performances of the three investigated antenna types are grouped and compared in Table 2.

Table 2: Performances of three investigated antenna types

\begin{tabular}{|c|c|c|c|}
\cline { 2 - 4 } \multicolumn{1}{c|}{} & $\begin{array}{c}\text { Resonance } \\
\text { frequency } \\
(\mathbf{G H z})\end{array}$ & $\begin{array}{c}\text { reflection } \\
\text { coefficient } \\
\left(\mathbf{S}_{\mathbf{1 1}} \mathbf{( d B}\right) \mathbf{)}\end{array}$ & $\begin{array}{c}\text { Bandwidth } \\
(\mathbf{G H z})\end{array}$ \\
\hline Antenna(a) & $\mathrm{f}_{1}=23,81$ & $-26,4$ & 12,35 \\
\hline \multirow{2}{*}{ Antenna (b) } & $\mathrm{f}_{1}=16$ & $-30,40$ & 1,35 \\
\cline { 2 - 4 } & $\mathrm{f}_{2}=20,7$ & $-41,70$ & 8,31 \\
\hline \multirow{3}{*}{ Antenna (c) } & $\mathrm{f}_{1}=14,92$ & $-16,57$ & 1,1 \\
\cline { 2 - 4 } & $\mathrm{f}_{2}=17,14$ & $-19,37$ & 0,97 \\
\cline { 2 - 4 } & $\mathrm{f}_{3}=20,43$ & $-29,37$ & 9,48 \\
\hline
\end{tabular}

\subsection{Effect of the ground plane size}

As reported in the literature, the variations of the ground plane topology and size can improve the characteristics of the antenna [7]. In this vision to evaluate the effect of the ground plane size on the performances of the proposed antenna, we have proceeded to the variation of the truncated rectangular ground plane length. In this case, a parametric study used by varying the length value between $2 \mathrm{~mm}$ and $8 \mathrm{~mm}$.

Figure 5 shows the variation of the reflection coefficient S11 as a function of the $\mathrm{Lg}$ parameter of the truncated ground plane length. 


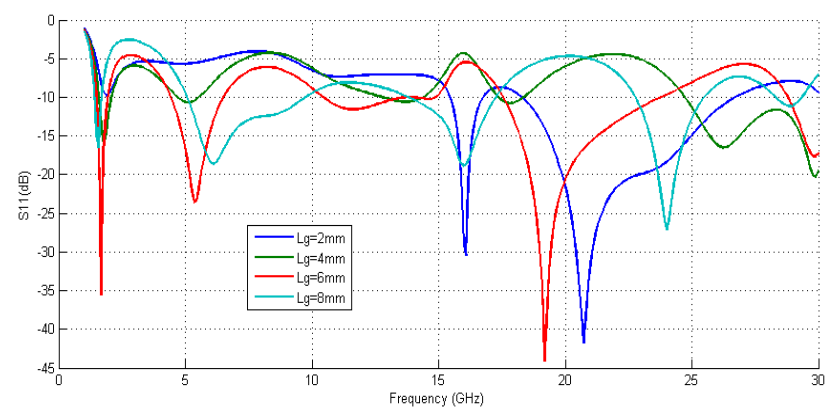

Figure 5: Simulated reflection coefficients curves for the antenna with various values of the $\mathrm{Lg}$ parameter

As previously predicted, the variation of the truncated ground plane size produces a great modification on the proposed antenna design characteristics. It is also observed that the antenna with $\mathrm{Lg}=2 \mathrm{~mm}$ value has the best performances compared to the other structures $(\mathrm{Lg}=4,6,8 \mathrm{~mm})$. To better show this comparison, we have grouped in Table 3 the different characteristics of the proposed antenna according to the $\mathrm{Lg}$ parameter.

Table 3 : different characteristics of the proposed antenna according to the $\mathrm{Lg}$ parameter.

\begin{tabular}{|c|c|c|c|}
\cline { 2 - 4 } \multicolumn{1}{c|}{} & $\begin{array}{c}\text { Resonance } \\
\text { frequency } \\
(\mathbf{G H z})\end{array}$ & $\begin{array}{c}\text { reflection } \\
\text { coefficient } \\
\left(\mathbf{d} \mathbf{S}_{\mathbf{1 1}}\right.\end{array}$ & $\begin{array}{c}\text { Bandwidth } \\
(\mathbf{G H z})\end{array}$ \\
\hline \multirow{2}{*}{$\mathbf{L g}=\mathbf{2} \mathbf{~ m m}$} & $\mathrm{f}_{1}=16$ & -30.48 & 1.31 \\
\cline { 2 - 4 } & $\mathrm{f}_{2}=20,72$ & $-41,79$ & 8,42 \\
\hline \multirow{2}{*}{$\mathbf{L g}=\mathbf{4} \mathbf{m m}$} & $\mathrm{f}_{1}=1.77$ & -16.5 & 0.0079 \\
\cline { 2 - 4 } & $\mathrm{f}_{2}=26.23$ & -16.49 & 0.49 \\
\hline \multirow{2}{*}{$\mathbf{L g}=\mathbf{6 m m}$} & $\mathrm{f}_{1}=5.44$ & -23.36 & 2.12 \\
\cline { 2 - 4 } & $\mathrm{f}_{2}=19.17$ & -44.03 & 6.09 \\
\hline \multirow{3}{*}{$\mathbf{L g}=\mathbf{8} \mathbf{m m}$} & $\mathrm{f}_{1}=6.12$ & -18.61 & 4.7 \\
\cline { 2 - 4 } & $\mathrm{f}_{2}=16.08$ & -18.69 & 3.38 \\
\cline { 2 - 4 } & $\mathrm{f}_{3}=24.00$ & -27.10 & 2.70 \\
\hline
\end{tabular}

In addition, from the results in section 3-1 and section 3-2, it can be concluded that the resonance frequency, the bandwidth and the gain of the proposed antenna can be controlled by the variation in the size of the slot on the radiant patch element or by the variation in the size of the truncated ground plane.

\section{ANTENNA RECONFIGURABILITY}

\subsection{Distribution of surface currents}

The study of the distribution of surface currents makes it possible to identify the areas of influence where the concentration of currents is higher[8]. This study enables us to determine the integration location of the inserted PIN diode. The addition of PIN diode redistributes the flow of currents and thus controls the resonance frequencies [9]. In Figure 6, we show the distribution of surface current at frequencies $\mathrm{f} 1=16 \mathrm{GHz}$ (Figure $6 \mathrm{a}$ ) and $\mathrm{f} 2=20.72 \mathrm{GHz}$ (Figure $6 \mathrm{~b}$ ).
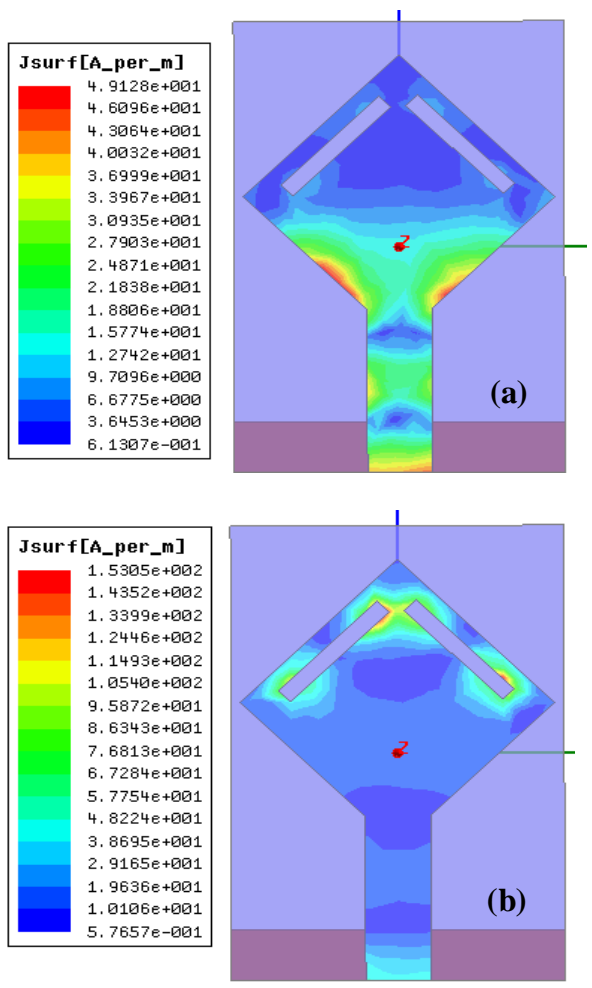

Figure 6 : Simulated surface current distribution at the frequencies: (a) $\mathrm{f} 1=16 \mathrm{GHz}$ and (b) $\mathrm{f} 2=20.72 \mathrm{GHz}$.

As indicated in Figure 6, the distribution of surface currents is stronger at the edge of the slots for $\mathrm{f} 1=16 \mathrm{GHz}$. For $\mathrm{f} 2=20.72 \mathrm{GHz}$, the distribution of surface currents is concentrated on the microstrip line. This result permits to set the integration locations of our PIN Diode. In addition, the last Figure shows that the surface currents are mainly concentrated on the outer contour of the slots and in the first part of the patch.

\subsection{D Radiation pattern}

Figure 7 shows the simulated $3 \mathrm{D}$ radiation pattern of the proposed antenna structure.

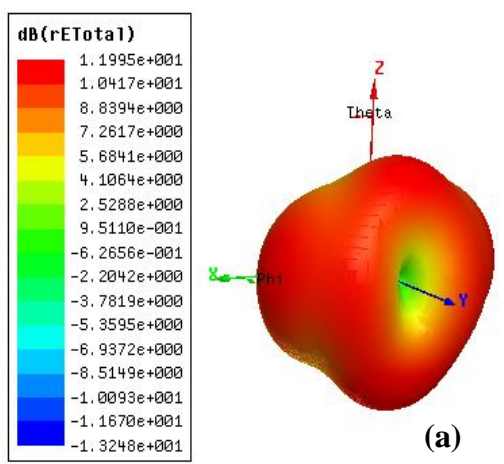




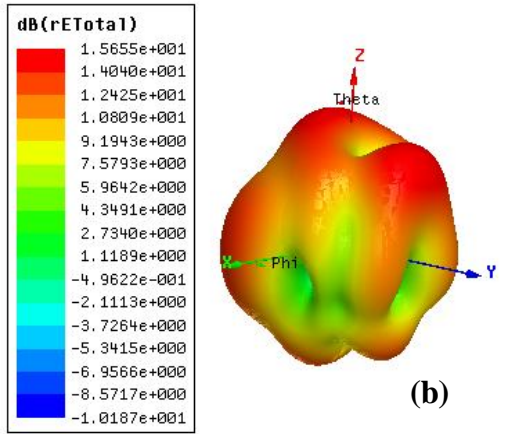

Figure 7 : Simulated result of Radiation pattern at the frequencies: (a) $\mathrm{f}=16 \mathrm{GHz}$ et (b) $\mathrm{f}=20.72 \mathrm{GHz}$.

As illustrated in Figure 7, the suggested antenna has directional radiation along the axes (ox and oy) for the resonance frequencies $(\mathrm{f} 1=16 \mathrm{GHz}$ and $\mathrm{f} 2=20.72 \mathrm{GHz})$.

\subsection{Reconfigurable antenna geometry}

After the localization of the concentration of the electric field on the proposed antenna structure, we insert the PIN diode in the microstrip line as indicated in Figure 1. In Ansoft HFSS simulation procedure, the integrated PIN diode is modeled using a lumped RLC boundary. The equivalent circuit model of the PIN diode in different status (ON/ OFF) is shown in Figure 8.

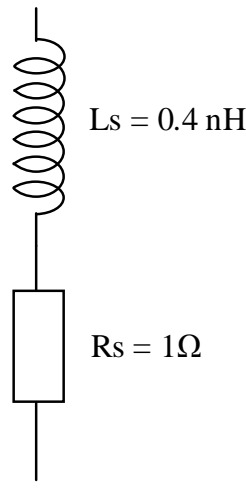

PIN diode ON

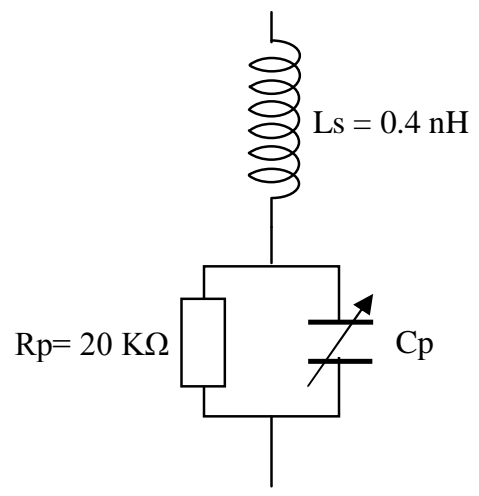

PIN diode OFF
Figure 8 : Linear Circuits equivalent of the integrated PIN diode

Working with the PIN diode can be easily explained through Figure 8. In forward bias, the diode is modeled with a resistance of $\mathrm{R}=1 \Omega$ in series with an inductance of $\mathrm{L}=0.4 \mathrm{nH}$. In reverse bias, it is modeled as a reverse parallel resistance $\mathrm{R}=20 \mathrm{k} \Omega$ with capacitance $\mathrm{C}$ (Variable Value) and inductance $\mathrm{L}=0.4 \mathrm{nH}$ [10]. The proposed values are: $\mathrm{C}=0.01 \mathrm{pF}, \mathrm{C}=0.1 \mathrm{pF}$ and $\mathrm{C}=0.5 \mathrm{pF}$ [11].

\subsection{Simulation results}

After the integration of the PIN diode on the proposed antenna structure as shown in Figure 1, the numerical simulation results of S11 are illustrated in Figure 9.

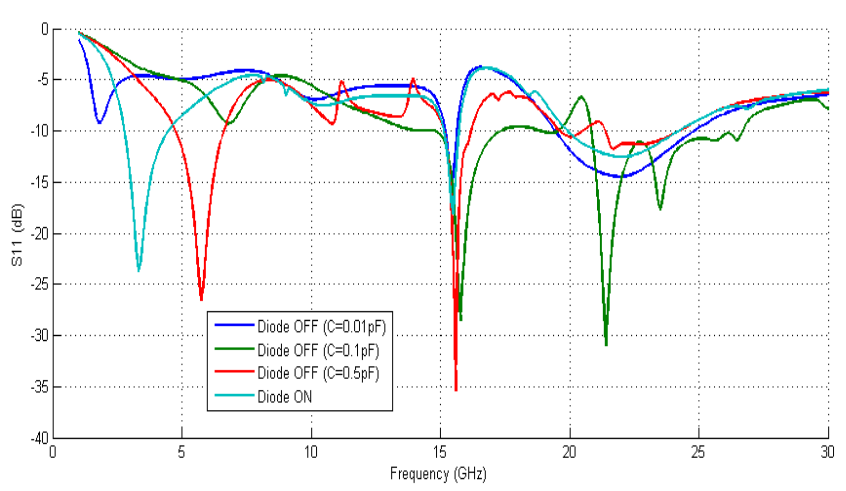

Figure 9 : Simulated reflection coefficient curves for the reconfigurable antenna

As shown in Figure 9, the proposed antenna structure shows multi-band behavior. In this configuration, the antenna covers new operating bands according to the values of the capacity of integrated diode. Multiband performance is due to the modification of the state of the PIN diode or by the variation of their capacity. In Table 4, we give the different simulated parameters as well as the integrated total capacity values of the PIN diode.

Table 4: Resonance frequencies according to the PIN diode state

\begin{tabular}{|c|c|c|c|c|}
\hline & & $\begin{array}{c}\text { Resonance } \\
\text { frequency } \\
(\mathbf{G H z})\end{array}$ & $\begin{array}{c}\text { reflection } \\
\text { coefficient } \\
\left(S_{11}(d B)\right)\end{array}$ & $\begin{array}{c}\text { Bandwidth } \\
\text { (GHz) }\end{array}$ \\
\hline \multirow{6}{*}{$\begin{array}{c}\text { DIODE } \\
\text { OFF }\end{array}$} & \multirow{2}{*}{$\mathrm{C}=0.01 \mathrm{pF}$} & $\mathrm{f}_{1}=15.79$ & -28.49 & 2.5 \\
\hline & & $\mathrm{f}_{2}=21.39$ & -30.98 & 5.89 \\
\hline & \multirow{2}{*}{$\mathrm{C}=0.1 \mathrm{pF}$} & $f_{1}=5.73$ & -26.58 & 1.83 \\
\hline & & $f_{2}=15.59$ & -35.41 & 1.06 \\
\hline & \multirow{2}{*}{$\mathrm{C}=0.5 \mathrm{pF}$} & $\mathrm{f}_{1}=3.32$ & -23.36 & 1.7 \\
\hline & & $f_{2}=15.5$ & -18.12 & 0.58 \\
\hline \multicolumn{2}{|c|}{ DIODE ON } & $f_{1}=15.5$ & -14.54 & 0.4 \\
\hline
\end{tabular}

Consequently, the results demonstrate that the variation in the capacitances of the integrated PIN diode on the proposed antenna structure grants good resonance frequency flexibility as displayed in Table 4.

Simulated results show that in ON condition, the reflection coefficient is $-16 \mathrm{~dB}$ from $20 \mathrm{GHz}$ to $25 \mathrm{GHz}$. When the PIN diode is in OFF state, the reflection coefficient is below $-35 \mathrm{~dB}$ as illustrated in Figure 9.
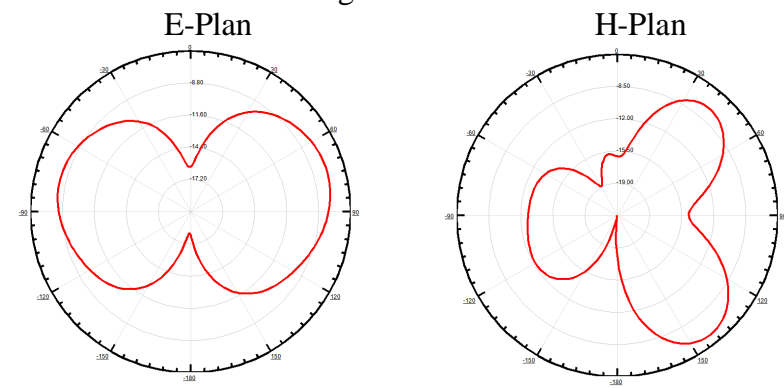

$\mathrm{F}=15.79 \mathrm{GHz}$ 


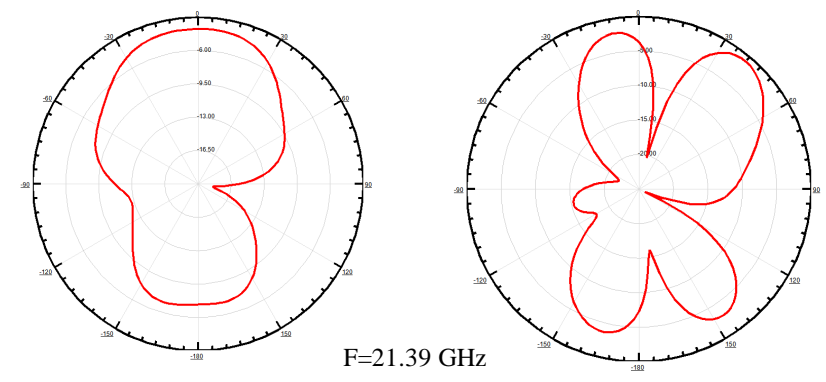

Figure 10 : Simulated 2D radiation pattern at resonant frequency of the proposed antenna at $\mathrm{C}=0.01 \mathrm{pF}$

According to Figure 10, the 2D radiation patterns on E-Plan $(\varphi=0)$ and H-Plan $\left(\theta=90^{\circ}\right)$ of the proposed antenna structure without PIN diode has a toroidal appearance, with omnidirectional radiation. When inserting the PIN diode, we observe a slight alteration of the radiation pattern. This change is accompanied by an increase in the gain values.

Table 5: Comparison Between Proposed Antenna and Reported Antennas

\begin{tabular}{|c|c|c|c|c|}
\hline Works & $\begin{array}{c}\text { Nbr of } \\
\text { integrated } \\
\text { components }\end{array}$ & $\begin{array}{c}\text { reflection } \\
\text { coefficient } \\
\text { maximum } \\
(|\mathbf{S} 11(\mathbf{d B})|)\end{array}$ & $\begin{array}{c}\text { Nbr of } \\
\text { exploited } \\
\text { bands }\end{array}$ & $\begin{array}{c}\text { Size } \\
\text { antenna } \\
\left(\mathbf{m m}^{2}\right)\end{array}$ \\
\hline$[12]$ & 4 & 28 & 2 & $40.4 \times 37.8$ \\
{$[13]$} & 6 & 20.164 & 3 & $26.9 \times 24.5$ \\
Our work & 1 & 35.41 & 7 & $18 \times 12$ \\
\hline
\end{tabular}

As indicated in Table 5, the previous research paper obtained more bands with integrating one electrical control component. It should also be noted that the proposed antenna has a reduced size. Moreover, changing the capacitance of the integrated diode allows also the shifting frequency around each resonant frequency.

\section{CONCLUSION}

We have designed a frequency reconfigured multiband antenna that can be capable of operating on different frequency bands with acceptable radiation performance. The design studied could be potentially useful in improving the insulation between two adjacent channels and doubling the available bandwidth of the system; however, the polarization bandwidth of the antenna may not be sufficient to meet the requirements of certain wireless communications. This problem would be solved by modifying the width of the rectangular slots in the radiant element.

\section{REFERENCES}

1. Huda A. Majid, Mohamad K. A. Rahim, Mohamad R. Hamid, Mohd F. M. Yusoff, Noor A. Murad, Noor A. Samsuri, Osman Ayop, and Raimi Dewan“ Wideband Antenna with Reconfigurable Band Notched Using EBG Structure",
Progress In Electromagnetics Research Letters, Vol. 54, pp 713, 2015.

2. Chung, K., J. Kim, and J. Choi, "Wideband microstrip-fed monopole antenna having frequency band-notch function,” IEEE Micro. Wirel. Comp. Lett., Vol. 15, pp 766$768,2005$.

3. Mohammad Ojaroudi and Noradin Ghadimi Mohammadi , "Reconfigurable Band-Notched Small Square Slot Antenna With Enhanced Bandwidth For Octave-Band, Multiresonance Applications", Microwave and Optical Technology Letters / vol. 56, no. 8,pp.1960-1965 august 2014.

4. Z Z Deng, J Gan, H Wei, H Gong, X Guo "Ka-band radiation pattern reconfigurable antenna based on microstrip MEMS switches", Progress In Electromagnetics Research Letters, Vol. 59, pp 93-99, 2016.

5. M. Borhani Kakhki, P. Rezaei, " Reconfigurable Slot Antenna with T-Shaped Strip in The Ground Plane for UWB/Wimax Applications", Conference Paper, January 2015.

6. M. Borhani, P. Rezaei, A. Valizade, “ Design of a Reconfigurable Miniaturized Microstrip Antenna for Switchable Multiband Systems",IEEE Antennas and Wireless Propagation Letters, Volume: 15, pp. 822 825 , sepember 2015.

7. El Mustapha Iftissane, Moulay Driss Belrhiti, Seddik Bri, Jaouad Foshi, Nawfal Jebbor, A Design and Analysis of Frequency Reconfigurable Antenna Embedding Varactor Diodes, Adv. Sci. Technol. Eng. Syst. J. volume 4 issue 6, pp.371-376 December 2019.

8. Ms. Pagire T. G, Design and impementation of Reconfigurable Antenna, International Research Journal of Engineering and Technology (IRJET), Volume : 04, pp. 2655 - 2660, June 2017.

9. Iftissane El Mustapha, Nawfal Jebbor, Foshi Jaouad, Moulay Driss Belrhiti, Bri seddik. Reconfigurable Slot Antenna for Ku-Band Applications, International Research Journal of Engineering and Technology (IRJET), Volume 8. No. 4, pp.1439-1444, April 2020.

10. Sonia Sharma, and Chandra C. Tripathi, "Frequency Reconfigurable U-Slot Antenna for SDR Application", Progress In Electromagnetics Research Letters, Vol. 55, pp.129-136, 2015.

11. Moulay Driss Belrhiti ; Bri Seddik ; Iftissane El Mustapha; Foshi Jaouad. Conception of Frequency Reconfigurable Multi-band Antenna, IEEE, 7th Mediterranean Congress of Telecommunications (CMT), 16 December 2019.

12. Pawan Kumar, Santanu Dwari, Rohit Kumar Saini, and Mrinal Kanti Mandal," Dual-Band Dual-Sense Polarization Reconfigurable Circularly Polarized Antenna", IEEE Antennas and Wireless Propagation Letters, Vol: 18, Issue: 1, Jan. 2019, pp. 64 - 68, 12 November 2018.

13. Raji George1, C. R. S. Kumar1, Shashikala Gangal, Makarand Joshi," Frequency Reconfigurable Pixel Antenna with PIN Diodes", Progress In Electromagnetics Research Letters, Vol. 86, pp.59-65, 2019. 